\title{
Fire in the Wildland-Urban Interface: Preparing a Firewise Plant List for WUI Residents ${ }^{1}$
}

Anna L. Behm, Alan J. Long, Martha C. Monroe, Cotton K. Randall, Wayne C. Zipperer, and L. Annie Hermansen-Baez ${ }^{2}$

This extension publication is a guide to making a firewise plant list to assist local homeowners with firewise landscaping. It includes a step-by-step method for determining whether or not a particular plant is appropriate for firewise landscaping. Extension agents, nursery personnel, landscape architects, or urban foresters may use this publication for preparing local firewise plant lists in the wildland-urban interface (WUI). These lists can be combined with the Florida Cooperative Extension Service publication "Selecting and Maintaining Firewise Plants” for homeowners and other interested groups.

\section{Firewise Landscaping Through Defensible Space}

In the South, the expanding wildland-urban interface consists of many homes adjacent to fire-prone natural areas. A wildfire risk/hazard assessment can assist homeowners and extension personnel in first identifying if firewise landscaping is necessary for an individual home. To be "firewise" is to be adequately prepared for the possibility of wildfire. Firewise has many components including community design, escape routes and plans, construction materials, and the landscaping around a home. The creation of defensible space is a landscape strategy for reducing the risk of damage from wildfires.

Defensible space surrounding a home allows for easy access by firefighting equipment and personnel, but also increases the chance of a home surviving even if firefighters are unable to reach each home.

In high risk areas, creating defensible space generally includes vertical and horizontal separation of plants surrounding a home. Branches of trees should be separated from plants beneath them by at least 10 feet. There should also be at least a 10-foot separation between branches of individual trees, and between branches and structures. Landscape plantings should be grouped into isolated landscape islands separated by less flammable materials such as maintained lawn, pathways, or gravel. Any landscape beds next to a home should consist of sparse, low-growing ground cover separated from the home by gravel or stones with no flammable landscaping materials in contact with the home. Plant arrangement is one of the most important factors affecting the survivability of a home during a wildfire.

1. This document is Circular 1453, one of the Fire in the Wildland-Urban Interface series of the School of Forest Resources and Conservation, Florida Cooperative Extension Service, Institute of Food and Agricultural Sciences, University of Florida. First published: July 2004. This factsheet is funded by the National Fire Plan through the Southern Center for Wildland-Urban Interface Research and Information, Southern Research Station, USDA Forest Service.

2. Anna L. Behm, Research Associate; Alan J. Long, Associate Professor; Martha C. Monroe, Associate Professor; and Cotton K. Randall, WUI Fire Project Coordinator, School of Forest Resources and Conservation, Institute of Food and Agricultural Sciences, University of Florida. Wayne C. Zipperer, Research Scientist; L. Annie Hermansen-Baez, Technology Transfer Coordinator, Southern Center for Wildland-Urban Interface Research and Information, Southern Research Station, USDA Forest Service.

\footnotetext{
The Institute of Food and Agricultural Sciences is an equal opportunitylaffirmative action employer authorized to provide research, educational information and other services only to individuals and institutions that function without regard to race, color, sex, age, handicap, or national origin. For information on obtaining other extension publications, contact your county Cooperative Extension Service office. Florida Cooperative Extension Service / Institute of Food and Agricultural Sciences / University of Florida / Larry R. Arrington, Dean.
} 


\section{Firewise Plant Lists}

The plant species within a firewise landscaping arrangement are important as well. Although all plants burn, some species are less flammable than others (Box 1). These less flammable plants are more desirable for firewise landscaping. Homeowners that are interested in implementing firewise landscaping commonly look for a list of firewise landscape plants to guide their selections. Equally important is informing homeowners about the plants that are highly flammable and should be avoided in firewise landscaping. The preparation of extension materials on firewise plants may present a challenge to natural resource professionals since information on flammability may be unavailable.

Firewise plant lists are most helpful when they include local plants adapted to local climate and soils. Also, cultural, social, and aesthetic factors dictate what kinds of plants and landscaping are locally desirable.

\section{Box 1. Defining Plant Flammability}

In a firewise landscaping context, flammability refers to the ability of a plant to ignite and transfer heat and/or flames to surrounding plants or structures. Plants are flammable for different reasons; some plants are highly ignitable, but burn quickly. Other plants are not easily ignitable, but can burn for a long time once ignited. Flammability is comprised of four components:

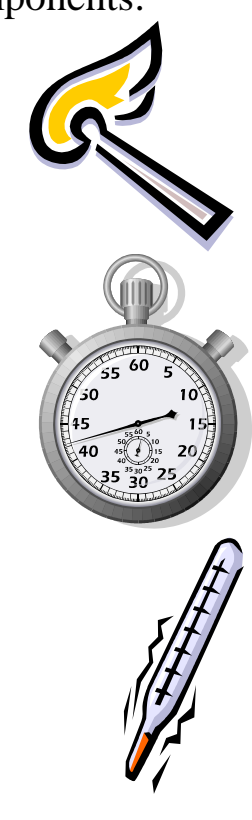

Ignitability: The time to ignition once exposed to an ignition source such as an ember or flame.

Sustainability: The duration a plant will sustain a fire.

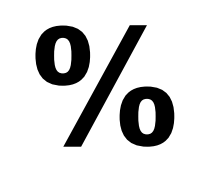

Combustibility: The rate of spread and rate of heat (or energy) given off from a burning plant.

\section{Creating Your Own Firewise Plant List}

Many characteristics influence how plants burn and not all of them are easy to assess. The step-bystep method in this publication will assist in determining whether or not different plant species are appropriate for firewise landscaping (Box 2). This method has been developed through a three-year plant flammability project by the University of Florida and the Southern Center for WUI Research and Information as well as related research from around the country. 
This step-by-step method was tested for repeatability and accuracy in the spring of 2004 through expert review, classroom testing, and results from comprehensive burn trials of southern landscape plants. The burn trials, conducted in March and May of 2004, tested the flammability of 34 southern shrub species. Four potted plants of each species were purchased from nurseries exposed to a natural gas ignition source at facilities operated by the National Institute of Standards and Technology (NIST) in Gaithersburg, Maryland. Many measurements of flammability were taken, including: time until ignition, heat release rate, and maximum flame height. Ranking of the 34 species tested at NIST by the method described below was generally similar to ranking based on peak heat release rates in the NIST tests.

\section{Box 2. Step-by-step method for creating a firewise plant list.}

Step 1: Identify the Plant Species

Step 2: Select Representative Plants

Step 3: Use the Flammability Key

Step 4: Rate the Species and Prepare your Document

Step 5: Compare the Results

\section{Step 1: Identify the Plant Species}

Think about what types of plants you would like to include in your list. Do you want to focus on native species, low-maintenance species, flowering shrub species, etc.? Once you identify the plant species that would be appropriate for the type of list you would like to make, you must then properly identify the plant species that you want to include in your firewise plant list, including both the common (including cultivar) and scientific names. The full scientific name is needed because not all species within the same genus have the same flammability and the same common name may be used for different species. Utilize plant identification keys, landscaping books, nursery personnel, and/or expert identification to help with proper identification.

\section{Step 2: Select Representative Plants}

Each species, or cultivar of a species, will have its own rating. To make a thorough assessment of flammability, select three individual plants of each species you would like to include in the final list. These plants should be mature, free of disease, and appear healthy. Also, landscape plant books can be helpful in describing the overall shape, average size, and growing conditions for different plant species as this information is needed in the following key. Landscape plant books also generally identify many of the characteristics needed to make the flammability assessment. In addition, information on the light, soil, and water requirements of different species is helpful to include in the final firewise plant list. It is important to consider the plant as it exists throughout the year and especially during your local fire season.

Examples of southern landscape plant identification books include:

Arnold, M. A. 2002. Landscape Plants for Texas and Environs. Stipes Publishing L.L.C., Champaign, IL.

Batson, W. T. 1984. Landscape Plants for the Southeast. University of South Carolina Press, Columbia, SC.

Dehgan, B. 1998. Landscape Plants for Subtropical Climates. University Press of Florida, Gainesville, FL.

Halfacre, R. G. and A. R. Shawcroft. 1989. Landscape Plants of the Southeast, $5^{\text {th }}$ edition. Sparks Press, Inc., Raleigh, NC. 


\section{Step 3: Use the Flammability Key}

The following key can be used to determine if a species is appropriate for a firewise plant list or not. Start with Number 1 and then move on to the indicated number when you find the option that best describes the species you are assessing. Be sure to keep track of how many "LESS FIREWISE" results you get for each species before reaching the end; ranking will depend on the number of "LESS FIREWISE" results that you find. If you reach a "NOT FIREWISE" result, you can immediately move to Step 4; a "NOT FIREWISE" result overrides any other results from the key. You can laminate the following pages containing the key and check the boxes with wipe-able markers (or markers for overhead projectors) in order to use the key repeatedly in the field. An optional form to record data is included on the final page of this document.

\section{Flammability Key}

Number

If Yes, Go to Number

First choose the type of plant it is (tree, palm or palm-like, shrub, vine, or herbaceous ornamental). Then move on to the number indicated to the right to begin the process. For example, if you were assessing the flammability of saw palmetto, you would then move to Number 5 for the next selection.

1. Tree....

Trees maintain vertical height in a landscape and can provide shade, windbreak, energy savings, wildlife habitat, and erosion control.

1. Palm or palm-like

Palms are typically found in the coastal plains of the South, bringing unique aesthetic value to home landscapes. Palms have leaves called fronds.

1. Shrub

Shrubs serve as privacy hedges, living fences, accent plants, wildlife habitat, erosion control, and a backdrop for herbaceous ornamentals.

1. Vine

Vines can be either herbaceous or woody and require a trellis, plant, or building for support.

1. Herbaceous ornamental, groundcover, or grass 14

Low-growing plants add color and variety to a landscape. Groundcovers are typically placed in landscape or foundation beds.

2. Conifer

Conifers have needle-like or scale-like leaves and include pines, hemlocks, spruces, junipers, cedars, and cypress.

2. Broadleaf.

Broadleaves have wide, broad leaves and include maples, oaks, elms, and many more.

3. Conifer sheds large amounts of leaves or needles (many pine species)

3. Conifer does not regularly shed leaves or needles.

4. $\square$ LESS FIREWISE; pine needles need to be periodically removed from roofs, other landscape plants, and ground near structures

5. Branches or fronds are low (less than 3 meters, or 10 feet above ground) ............................................ 6

5. Good separation between ground and branches or fronds (at least 3 meters, or 10 feet) ......................... 7

6. $\square$ LESS FIREWISE; trees must be pruned and dead branches and fronds removed to have a more firewise habit (up to 3 meters, or 10 feet if possible)

7. Trunk has papery bark or loose fibers

7. Trunk does not have papery bark or loose fibers 
8. $\square$ LESS FIREWISE; papery bark or loose fibers may act as ladder fuels, proper placement is

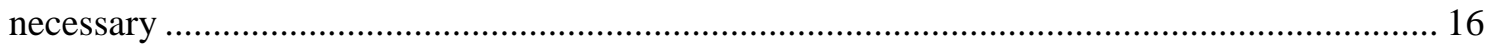

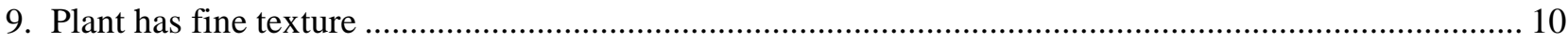

Texture is a term used to describe the overall appearance of a plant from a distance. From a

distance, about 3 meters (10 feet), it is not easy to distinguish each individual leaf or branches on plants with a fine texture. Examples include boxwood, dwarf yaupon, spirea, and junipers.

9. Plant has medium texture

9. Plant has course texture

Many azalea and holly species are in this plant texture category.

From a distance, about 3 meters (10 feet), it is easy to distinguish each individual leaf or branch. Examples include hydrangea, beautyberry, and witch hazel.

10. $\square$ LESS FIREWISE; proper placement and routine pruning necessary .....

11. Plant is very dense

These shrubs are so dense that it is very difficult to place your hand in the shrub and touch a main stem. These plants have dense branches and include plants like boxwood and junipers.

11. Plant is moderately dense 16

These shrubs are dense enough that you can't clearly see through them, but it is reasonably easy to place your hand in the shrub and touch a main stem.

11. Plant is sparsely dense

Some plants have open branching patterns, making it easy to see through the shrub. Shrubs

in this category include American beautyberry, fatsia, and some hydrangeas.

12. $\square$ LESS FIREWISE; proper placement and routine pruning necessary

13. $\square$ NOT FIREWISE; GO TO STEP 4. Vines are extremely flammable as they typically add fuel directly to a structure, or make ladder fuels connecting surface fuels to aerial fuels.

14. Grass (in family Poaceae or Gramineae) $>1$ foot tall. 15

14. All other herbaceous ornamentals, short grasses, or grass-like herbs. 16

15. $\square$ NOT FIREWISE; GO TO STEP 4. Regardless of how many “LESS FIREWISE” results you may get, tall grasses are extremely flammable because of their ability to rapidly carry fire.

16. Plant retains dead leaves for more than two months of the year................................................... 17

16. Plant does not usually retain dead leaves, except when in the process of shedding leaves ............... 18

17. $\square$ NOT FIREWISE; GO TO STEP 4. Regardless of how many “LESS FIREWISE” results you receive for this species, plants that retain dead foliage throughout the year are extremely flammable. Dead foliage has very low foliar moisture content and is therefore highly susceptible to ignition.

Make sure leaves are not poisonous before touching them.

18. Leaves have a waxy coating..... 19

These plants have leaves with a very identifiable waxy leaf. Wax myrtle (Myrica cerifera) and gallberry (Ilex glabra) are examples of plants with waxy leaves.

18. Leaves do not have a waxy coating 20

19. $\square$ LESS FIREWISE; proper placement and maintenance necessary ............................................... 20

20. Species is seriously susceptible to disease or insect pests 21

Plants seriously susceptible to disease are likely to become stressed and have less vigorous growth. When this happens, foliage has lower foliar moisture content and a greater number of dead leaves are retained.

20. Species is not seriously susceptible to disease or insect pests .... 
21. $\square$ LESS FIREWISE; make note of disease or pest, routine monitoring and appropriate treatment for the disease or pest is recommended ................................................... 22

22. Plant is evergreen (retains leaves throughout the year) ................................................................ 23

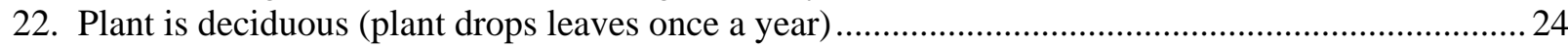

23. $\square$ LESS FIREWISE; proper placement and maintenance necessary ............................................... 24

24. FINISHED; GO TO STEP 4

\section{Step 4: Rate the Species and Prepare your Document}

Please select one from the following four categories. If after finishing the key you...

...had any "NOT FIREWISE" result (regardless of any "LESS FIREWISE” results), then that species is... $\square$ NOT FIREWISE (extreme flammability): These species should not be placed on firewise plant lists. These species could be placed on a list of flammable plants to be avoided in firewise landscaping.

...had three or more "LESS FIREWISE" results, then that species is...

$\square$ AT-RISK FIREWISE (high flammability): Avoid placing these species on firewise plant lists. Only place on list with ample personal wildfire experience that indicates that this species does not readily burn in wildfire conditions. These species could be placed in the landscape beyond defensible space.

...had one or two "LESS FIREWISE" results, then that species is...

MODERATELY FIREWISE (moderate flammability): These species can still be placed on a firewise plant list. Any routine maintenance needed to keep the plant less flammable should be noted with the entry of this species. Personal wildfire experience can also be utilized with these species to more strongly rank the species as firewise.

...had no "LESS FIREWISE" results, then that species is...

FIREWISE (low flammability): These species have no known characteristics of high flammability. These species are very appropriate for placement on firewise plant lists.

\section{The Problem with Moisture Content}

The moisture content of leaves is a major contributor to how the plant is going to burn when exposed to fire; the more water contained in the leaves, the less flammable the plant. However, moisture content is a difficult thing to measure accurately, and especially difficult to assess quickly. This is because moisture content may change throughout the life span of a plant, over seasons, and even throughout the day. Moisture content is not used in this key to rank the flammability of a species, but it remains an important variable. Deep and infrequent irrigation during establishment can encourage a plant to grow deeper roots, reducing plant stress during dry periods. Keeping plants vigorous and healthy helps to maintain moisture content in the leaves. Some plants, especially many succulents, have high moisture content in their leaves. Examples of succulents include aloe (Aloe), moss rose (Portulaca), stonecrop (Sedum), and hens and chicks (Echeveria). These species are firewise plants that can be placed on a firewise plant list if available and suitable for your area.

\section{Keep in Mind}

- $\quad$ The term "fire resistance" in fire ecology literature refers to the ability of a plant to survive a fire. This term may apply to native plants that are highly flammable, but generally resist being killed by wildfire.

- $\quad$ There are no "fireproof" plants and all plants will burn in extreme weather or fire conditions. 
- $\quad$ Diseased plants are more flammable because of the loss of vigor and increased amount of dead (and therefore dry) plant material. It is important to express the need for the "right plant, right site" concept in plant selection.

- $\quad$ Species within the same genus DO NOT always have the same flammability. Assess each species individually.

- $\quad$ The flammability of a given plant will change over time as the seasons change and the species matures.

- $\quad$ Evergreen plants tend to have lower moisture content, and higher flammability, than deciduous plants in the spring, when the previous years leaves begin to dry out and fall off the plant.

- It is important to state clearly how the list was prepared. If this methodology was used, this publication should be cited. This will assist potential users in establishing how the list was developed.

- It is important to include the following information for each species because it gives the information that would be necessary in selecting an appropriate species:

- Common and scientific names

- USDA Plant Hardiness Zone (http://www.usna.usda.gov/Hardzone/)

- Flowering season and flower color

- Light requirements

- Soil requirements

- Water requirements

- Native or non-native

- Wildlife benefits

- Routine maintenance needed to maintain low flammability

- Additional comments (showy flowers, poisonous to pets, messy fruits, etc.)

\section{Step 5: Compare the Results}

The method outlined in this publication is a general guide for identifying firewise plants (also highly flammable plants) for lists to be made available to homeowners. However, we recommend using multiple sources of information (Box 3) to develop your final list. Any discrepancies should be evaluated. There may be benefits to organizing local focus groups to create a firewise plant list with input from many different experts. 


\section{Box 3. Sources of Information or Review}

- Wildfire Professionals

- Professionals have fire knowledge of local plants

- Examples:

- USDA Forest Service

- State forestry agency (http://www.stateforesters.org/SFlinks.html)

- Local fire fighting agency

- Southern Center for Wildland-Urban Interface Research and Information, USDA Forest Service

- http://www.interfacesouth.org/

- Brochures, links, state contacts, and fire research updates

- Use the "Contact Us" page to request specific information, such as a local "Firewise" contact in your area.

- Cooperative Extension Service

- Information on local horticulture, landscaping, fire behavior, and fire ecology

- Contact your local Cooperative Extension Service office through your state universities or by clicking on your state through the Web site: http://www.reeusda.gov/1700/statepartners/usa.htm

\section{Conclusion}

Firewise plant lists are increasingly requested by residents and other interested groups in the WUI. These lists can be a helpful educational tool for the general public when they inquire about wildfire preparedness and firewise landscaping. By using this tested methodology to rank the flammability of landscape plants, you can create a publication listing firewise plants specific for your local area. Citing the methodology used to create your list will also prove very helpful for other extension agents or professionals who may use your list. Including horticultural requirements and landscaping attributes can assist residents and landscape professionals in selecting the "right plant" for the "right site". After completing your publication, please send a copy of the list to the Southern Center for Wildland-Urban Interface Research and Information at 408 W. University Ave., Suite 306, USDA Forest Service, Gainesville, FL 32601. It can also be sent by email (ahermansen@fs.fed.us) or fax (352-376-4536). Sending the list to the Southern Center for Wildland-Urban Interface Research and Information will assist the Center in becoming a clearinghouse for southern WUI materials.

\section{Acknowledgements}

We acknowledge the Building and Fire Research Laboratory (BFRL) at the National Institute of Standards and Technology (NIST), Gaithersburg, Maryland, for use of facilities and personnel support during burn trials to test this ranking system. Specifically we thank Alexander Maranghides with the BFRL. We thank Bob Campbell of the Georgia Forestry Commission and Fred Turck of the Virginia Division of Forestry for their input into this project, and the many students who pilot-tested this extension publication. 
Preparing a Firewise Plant List for Homeowners

Page 9

\section{Optional Form to Record Results}

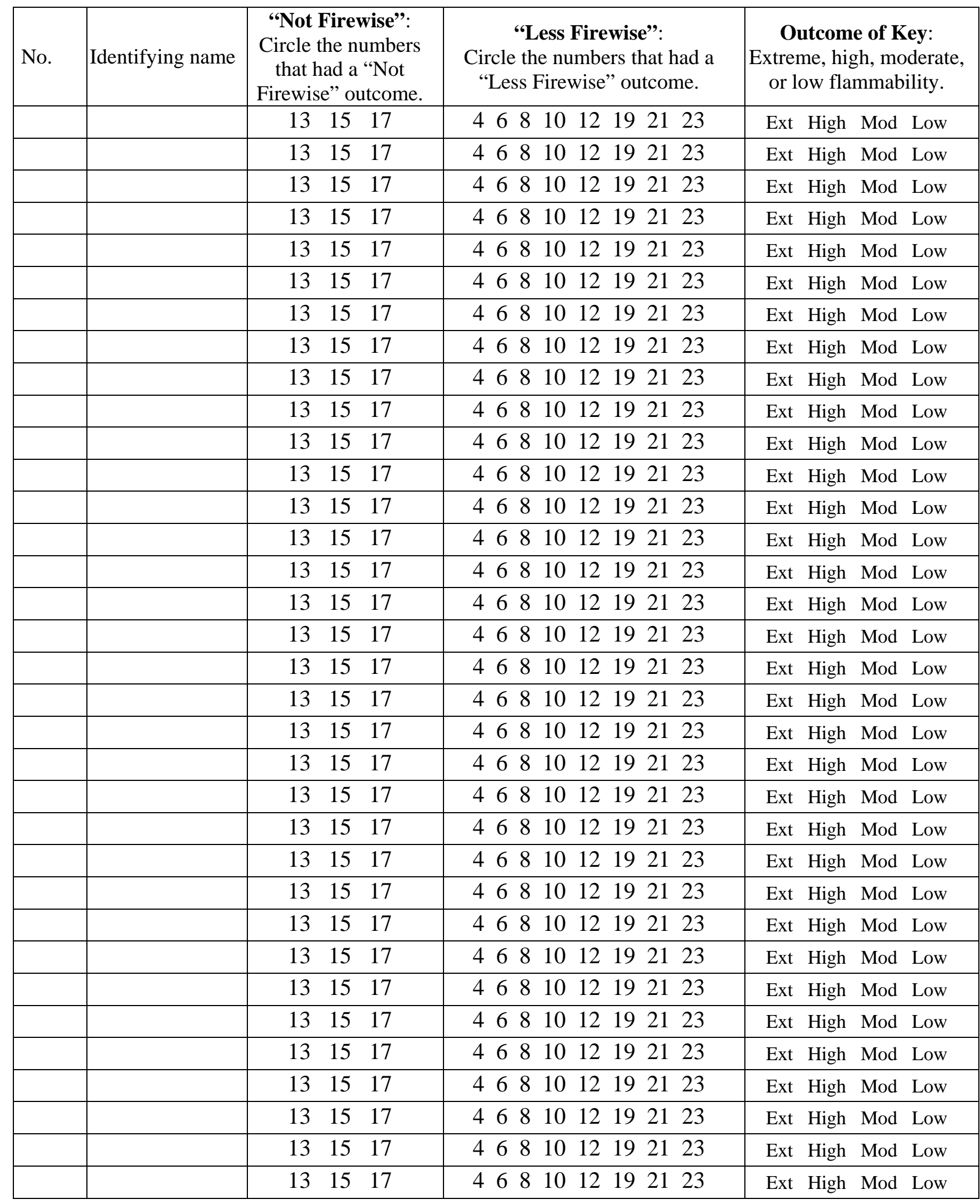

